\title{
Acceptance and Knowledge of Family Planning Among Muslim Women in Rural Villages of Kelantan
}

\author{
Norsa'adah Bachok, MComMed;'1 Asmani Abdul Razak, BDS;2 Noorliza Mastura Ismail, MSc;3 \\ Tengku Norbanee Tengku Hamzah, MComMed ${ }^{1}$ \\ IUnit of Biostatistics and Research Methodology, School of Medical Sciences \\ 2Department of Community Medicine, School of Medical Sciences \\ 3Department of Community Dentistry, School of Dental Sciences \\ Universiti Sains Malaysia \\ Kelantan, Malaysia
}

\begin{abstract}
:
Objectives: To determine family planning practices among Muslim women in rural villages and evaluate their knowledge regarding the reproductive system and the effectiveness of contraceptive methods.

Study Design: A population survey was conducted among 173 consented married women 18 years and older from 200 randomly selected households in rural villages of Kelantan.

Results: The rate of using family planning methods among the population was $31.8 \%$ (95\% CI: 24.8-38.8\%). The most popular contraceptive method was oral contraceptive, followed by injectables, traditional methods, intrauterine devices, and implants. The criteria of ideal family planning methods were safety of use, ease of use, cost, and effectiveness of preventing. Most women had poor knowledge regarding reproduction and family planning methods. The use of family planning methods was influenced by ethnicity and educational level.

Conclusions: The acceptance of family planning methods and the level of knowledge among women in these villages were poor. More health promotion campaigns are needed to enhance the use of family planning.
\end{abstract}

Keywords: family planning, contraceptives, rural health, Islam, knowledge.

Introduction

T he population structure of rural areas in Malaysia is shaped like a pyramid with the base, or largest portion, representing children

Correspondence should be directed to

Norsa'adah Bachok, MComMed

Unit of Biostatistics and Research Methodology

School of Medical Sciences,Universiti Sains Malaysia

16150 Kubang Kerian, Kelantan, Malaysia

Telephone: 609-7664896; Fax: 609-7653370

E-mail:norsaadah@kb.usm.my and the top, or smallest portion, representing the elderly. ${ }^{1}$ Malaysia is still considered a developing country. Family planning programs in Malaysia were introduced in the 1930s and have expanded to reduce the crude birth rate to $21.7 / 1000$ in $2002 .^{2}$ Government, nongovernmental agencies, private hospitals, and clinics play a major role in providing such services. In 2002, the Ministry of Health provided $75.8 \%$ of the family planning services, nongovernment agencies provided $15.1 \%$, and other agencies provided the remaining percentage. ${ }^{3}$ Women consenting to family planning programs in Malaysia used birth control pills, condoms, and intrauterine 
devices (IUDs). They also relied on sterilization.

The contribution of Malaysian women to family and society has led to an increase in the literacy rate, provided more opportunities for education and employment among women, and has improved the family socioeconomic status, thereby directly influencing the decisions pertaining to family planning. An increased knowledge of family planning and the desire to improve family living standards among women has led to the acceptance of contraception. A qualitative study among Indonesians reported valid reasons for using family planning methods include the financial burden of large families and as the means of improving economic situation of families. ${ }^{4}$ Family planning allows adequate spacing between pregnancies and enables couples to systematically plan the number of children they will have, thereby limiting family size. These factors contribute to better health of infants, children, and women. By limiting family size, children may receive better nutrition, which is vital to survival of children in developing countries. In poorer countries, complications related to pregnancy and childbirth are common causes of maternal death. ${ }^{5}$ In addition to other factors, family planning programs in Malaysia have decreased the maternal mortality rate by $80 \%$ and the infant mortality rate by $68.2 \%$ in the period from the from the 1950 s to the 1970 s. ${ }^{6}$ Family planning can also prevent pregnancy at very early or late periods in women's reproductive lives, when maternal and fetal risks are the greatest. It can help avoid unintended pregnancies that may lead to illegal or dangerous abortions. A study among women in Istanbul reported that $27.2 \%$ did not desire their last pregnancy and $86.8 \%$ did not want to have anymore children. However, only $81.3 \%$ were using some form of contraceptive. ${ }^{7}$ Relief from the burden of childbearing and rearing has encouraged women to pursue higher education, training, and employment or professional advancement. Subsequently, not having children has contributed to improved household income and socioeconomic status. Women who are better educated, have a higher socioeconomic standing, and have two or more children are more likely to use contraceptives. ${ }^{8}$ Cultural norms about family size, community pressure to bear children, a high level of religious adherence, employment opportunities for women, male perceptions of family planning, and the availability of family planning services affect women's reproductive health decisions. ${ }^{9}$

A previous community study in rural areas of Kelantan showed that $55 \%$ of families had five or more family members and $33.7 \%$ of the community consisted of children 12 years old or younger. ${ }^{1}$ We hypothesised that the practice of family planning in these villages was poor. Furthermore, the status of family planning acceptance and practices among Muslim women in rural area of Malaysia is not well known. Thus the objective of the present study was to determine family planning practices among Muslim women in rural areas and to evaluate their knowledge regarding the reproductive system and the effectiveness of various contraceptive methods.

\section{Materials and Methods}

Kelantan is a northeastern state of Malaysia. Mukim Che Latiff is a rural area in the Kota Bharu District, Kelantan, and consists of four villages: Kuala Besar, Tapang, Pantai Mek Mas, and Telok Katak. It had an estimated population in 2004 of 1286 people, of which 598 inhabitants were men and 688 were women. A majority of villagers were ethnic Malays (97\%), followed by Cambodians (2\%), Chinese (1\%), and others such as Indians and Thais. Most were Muslims, and their predominant occupation was fishing. ${ }^{1}$

This community survey was conducted in January 2005. Two hundred households were randomly selected from 285. Out of the 200 selected households, only 192 (81\%) were available and consented to the study, while others refused or were not at home at the time of study. Trained interviewers used a structured questionnaire to interview 173 married women 18 years old and older from the selected households. Only married women were included since contraceptive use implies sexual activity, which is forbidden for unmarried Muslim women. Only one married woman per household was interviewed. Mentally ill and disabled women were excluded. The questionnaire consisted of sociodemographic characteristics, family planning methods, knowledge regarding the reproductive system, and the effectiveness of family planning methods. Each question in the knowledge segment was assigned specific scores: a score of 2 for correct, 0 for incorrect, and 1 for undecided answers. Total scores were used for analysis. The questionnaire was pretested for reliability, and the Cronbach alpha was 0.82 . 
Data were analyzed using SPSS version 11.0. Continuous variables were summarized as mean and standard deviation (SD) or median and interquartile range (IQR), depending on the normality of distribution and categorical variables in frequency and percentage. Frequency, percentage, and a 95\%-confidence interval (CI) were calculated for the rate of family planning acceptors. Differences of percentages between those who practiced family planning and those who did not were analyzed with chi-square test, while the difference of means were analyzed using the independent t-test. The level of significance was set at $p<0.05$. Multiple logistic regression was used to determine factors influencing the acceptance of family planning. The acceptance was considered as a dichotomous binary outcome. The stepwise backward elimination procedure was used to select significant variables in the model. The final model was tested and confirmed for fitness using Hosmer-Lemeshow goodness-of-fit test. The crude odds ratios (OR), adjusted OR, and 95\% CIs were estimated.

\section{Results}

The rate of using family planning methods for at least one month at any point in the respondents' lives was $31.8 \%$ (95\% CI: $24.8,38.8 \%$ ). Figure 1 shows that the most popular method was oral contraceptive pills, followed by injectables, traditional methods, IUDs, and implants. None of the women used condoms or spermicide; practiced the rhythm method, withdrawal, or exclusive breast-feeding; or had been sterilized or had a husband who was sterilied. Figure 2 displays the criteria for ideal family planning methods according to these women, which included safety of use (34.5\%), ease of use (18.9\%), affordability (15.6\%), and effectiveness (15.5\%).

Table 1 shows the effectiveness of family planning methods.

Table 2 shows the responses to knowledge questions regarding family planning methods and the reproductive system. The majority answered "undecided" (44.5-73.4\%), of which the highest percentage did not know that fertilization of the ovum occurs in the fallopian tube. Most women also did not know when the method begins to be effective to prevent pregnancy. Only $42.2 \%$ claimed that they have adequate knowledge regarding family planning methods.

Tables 3 and 4 compare family planning users and nonusers sociodemographic characteristics, obstetric history, and knowledge in an univariate analysis.
There were significant associations between users and age $(p<0.001)$, educational level $(p<0.001)$, knowledge about PAP smears $(p<0.001)$, and practice of breast self-examinations (BSE) $(p=0.003)$. Multiple logistic regression showed that family planning practice was influenced by ethnicity (non-Malay $\mathrm{OR}=6.03$, $95 \%$ CI: 1.61, 22.53) and educational level (secondary education or higher OR $=5.96,95 \%$ CI: $2.72,13.09$ ).

\section{Discussion}

The acceptance of family planning among Muslim women in these rural villages was poor (31.8\%). This was in contrast with other studies in the developed countries such as $72.5 \%$ in Canada, $64-73 \%$ in America, ${ }^{10}$ as well as in less developed countries such as $48 \%$ in Indonesia, ${ }^{4} 53 \%$ in Jordan, ${ }^{9} 54.8 \%$ in Eastern Turkey, ${ }^{11}$ and $37.8-45.2 \%$ in rural India. ${ }^{12,13}$ The promotion and availability of family planning services by the government, as well as socioeconomic and demographic compositions, urbanization, and religious devotion of the community account for the variation in the acceptance of family planning. ${ }^{4}$

Sociocultural and religious unacceptability of contraception is an important obstacle to family planning. ${ }^{14}$ Khor reported that rural Malays with a low socioeconomic status considered an ideal family to include many children. ${ }^{15}$ Many Malays still have this traditional belief that lends to a larger family size. They have many children at an earlier age and were less likely to use contraceptives..$^{14}$ In our study, Malays were significantly less likely than non-Malays to accept family planning. In many cultures, women gain status through childbearing. When women have smaller families, they may lose the security of traditional roles and face difficult challenges. ${ }^{16}$ To many Malay families, having many children represents wealth and security later in life because they can help with chores and provide support to their parents as they age. The Muslim faith also states that having many children who pray for the parents after they die may direct them to paradise in the after life. Another possible barrier to the acceptance of family planning among Muslim women includes the belief that Islam forbids contraception ${ }^{17}$ and preventing conception is a sin. ${ }^{11}$ It is important to highlight that Islam generally allows reversible contraceptive methods. ${ }^{9}$ A study among Muslim religious leaders reported that 82-98\% believed that family planning is in keeping with the tenets of Islam, but only $36 \%$ had preached about it. 18

Misconceptions about contraceptive methods 
Table 1. The effectiveness of the family planning methods according to the respondents.

\section{Frequency (\%)}

\begin{tabular}{lcccc} 
& Very effective & Effective & Less effective & Undecided \\
\hline Pills & $25(14.5$ & $29(16.8)$ & $16(9.2)$ & $103(59.5)$ \\
Injectables & $17(9.8)$ & $27(15.6)$ & $7(4.0)$ & $122(70.5)$ \\
Implants & $3(1.7)$ & $22(12.7)$ & $7(4.0)$ & $141(81.5)$ \\
IUDs & $9(5.2)$ & $20(11.6)$ & $12(6.9)$ & $132(76.3)$ \\
Condom & $1(0.6)$ & $13(7.5)$ & $22(12.7)$ & $137(79.2)$ \\
Tubal ligation & $20(11.6)$ & $16(9.2)$ & $5(2.9)$ & $132(76.3)$ \\
Vasectomy & $12(6.9)$ & $10(5.8)$ & $7(4.0)$ & $144(83.2)$ \\
Spermicidals & $2(1.2)$ & $4(2.3)$ & $14(8.1)$ & $153(88.4)$ \\
Traditional method & $2(1.2)$ & $14(8.1)$ & $33(19.1)$ & $124(71.7)$ \\
Withdrawal method & $1(0.6)$ & $14(8.1)$ & $24(13.9)$ & $134(77.5)$ \\
Rhythm method & $2(1.2)$ & $15(8.7)$ & $24(13.9)$ & $132(76.3)$ \\
Exclusive breast feeding & $6(3.5)$ & $23(13.3)$ & $18(10.4)$ & $126(72.8)$ \\
& & & & \\
\hline
\end{tabular}

Table 2. The responses of the respondents regarding family planning methods and the reproductive system.

Frequency (\%)

\begin{tabular}{lccc} 
Knowledge & Yes & No & Undecided \\
\hline 1. Have adequate knowledge regarding family planning methods* & $35(42.2)$ & $7(8.4)$ & $41(49.4)$ \\
2. Reproductive age of women is 15 to 49 years & $77(44.1)$ & $6(3.5)$ & $90(52.4)$ \\
3. Ovulation occurs 14 days before menses & $85(49.1)$ & $11(6.4)$ & $77(44.5)$ \\
4. Fertilization of the ovum occurs in fallopian tube & $37(21.4)$ & $9(5.2)$ & $127(73.4)$ \\
5. Women older than 35 years are not encouraged to take hormones & $43(24.9)$ & $29(16.8)$ & $101(58.3)$ \\
6. Pills are effective immediately after taking them & $26(15.0)$ & $41(23.7)$ & $106(61.3)$ \\
7. Injectable method is effective immediately after administration & $44(25.4)$ & $21(12.1)$ & $108(62.5)$ \\
8. IUD is effective immediately after insertion & $46(26.6)$ & $9(5.4)$ & $118(68.3)$ \\
\hline
\end{tabular}

*Some respondents did not answer this question.

such as the possibility of IUD displacement to the chest, interference with the sexual relationship, 4 and increased risks of infertility, cancer and pelvic pain ${ }^{11}$ reduce use of family planning methods. A study in Sudan reported that $85 \%$ of the respondents perceived contraception as a risk to their health and fertility and therefore regarded it as unacceptable. ${ }^{19} \mathrm{~A}$ U.S. study found when unplanned pregnancies occurred, most women reported they did not expect to have sexual intercourse and did not think they would become pregnant. 20
Women often lack the right to make decisions for themselves and frequently need approval from their husband or other family members before they can practice in family planning. Husbands, in-laws, and others can have strong opinions against contraceptive use and may see it as an obstacle to the extension of family lineage or as a challenge to traditional views about family authority. ${ }^{16}$ Objection from husbands was one of major reasons for wives to refuse or stop using contraceptives, especially among the Muslim women. ${ }^{11,13,16}$ 
Table 3. Comparison between family planning users and nonusers regarding sociodemographic characteristics and obstetric history using $\chi 2$ or Fisher exact tests.

Frequency (\%)

\begin{tabular}{|c|c|c|c|c|}
\hline Variable & $\begin{array}{l}\text { Practices } \\
\text { family planning } \\
\mathrm{N}=55\end{array}$ & $\begin{array}{l}\text { Does not practice } \\
\text { family planning } \\
\mathrm{N}=118\end{array}$ & $\begin{array}{l}\chi^{2} / \text { Fisher } \\
\text { exact test (df) }\end{array}$ & $P$ value \\
\hline Ethnic group & & & & 0.140 \\
\hline Malay & $49(30.4)$ & $112(69.6)$ & & \\
\hline Non-Malay & $6(50.0)$ & $6(50.0)$ & & \\
\hline Education level & & & $17.961(1)$ & $<0.001$ \\
\hline Below secondary education & $15(17.0)$ & $73(83.0)$ & & \\
\hline Above secondary education & $40(47.1)$ & $45(52.9)$ & & \\
\hline Occupation & & & $3.510(1)$ & 0.061 \\
\hline Homemaker & $40(28.6)$ & $100(71.4)$ & & \\
\hline Employed & $15(45.5)$ & $18(54.5)$ & & \\
\hline Menstrual cycle & & & $0.111(1)$ & 0.740 \\
\hline Regular & $45(32.4)$ & $94(67.6)$ & & \\
\hline Irregular & $10(29.4)$ & $24(70.6)$ & & \\
\hline Pregnant & & & & 0.588 \\
\hline Yes & $3(33.3)$ & $6(66.7)$ & & \\
\hline No & $52(31.7)$ & $112(68.3)$ & & \\
\hline Familiar with PAP smears & & & $15.840(1)$ & $<0.001$ \\
\hline Yes & $45(43.3)$ & $59(56.7)$ & & \\
\hline No & $10(14.5)$ & $59(85.5)$ & & \\
\hline Has had a PAP smear & & & $1.944(1)$ & 0.163 \\
\hline Yes & $34(47.9)$ & $37(52.1)$ & & \\
\hline No & $11(33.3)$ & $22(66.7)$ & & \\
\hline Practicing breast self-examinations & & & $9.093(1)$ & 0.003 \\
\hline Yes & $25(48.1)$ & $27(51.9)$ & & \\
\hline No & $30(24.8)$ & $91(75.2)$ & & \\
\hline
\end{tabular}

The safety of contraceptives was another major concern among respondents. Similarly, other studies also reported that side effects were a serious concern for women who used contraceptives ${ }^{13,17}$ and also among those who did not use contraceptives. ${ }^{21}$ In Indonesia, 31\% of women who used oral contraceptives, injectables, or implants reported experiencing problems such as headaches, while women who used injectables or IUDs reported menstrual irregularities. ${ }^{4}$ Menstrual problems can reduce the quality of life for Muslim women whose religion prevents a menstruating woman from fasting, praying, having, sex or touching the holy book. ${ }^{4}$ Furthermore, women may be reluctant to continue certain family planning methods based on negative past experiences ${ }^{4,20}$ such as pain during insertion of an IUD, unfriendly services, and lack of privacy during consultation. Unexpected side effects, failure to obtain a desirable method of contraceptive, and bad past experience may lead women to rejecting family planning. However, adequate counseling about side effects and easy access to family planning services when problems arise may help to prevent discontinuation of contraceptives. Service providers also need to be sensitive, customer friendly, and able to provide emotional support as well as education on family planning.

Most women in Malaysia are fortunate to have a range of contraceptive methods from which to choose; although some methods, such as female con- 
Table 4. The comparison between family planning users and nonusers regarding sociodemographic characteristics, obstetric history, and mean total knowledge score using the $t$ test.

\section{Mean (SD)}

\begin{tabular}{lcccc} 
& $\begin{array}{l}\text { Practices } \\
\text { family planning } \\
\text { Variable }\end{array}$ & $\begin{array}{l}\text { Does not practice } \\
\text { family planning } \\
\mathrm{N}=118\end{array}$ & t test (df) & P value \\
\hline Age (year) & $35.7(8.8)$ & $44.0(12.7)$ & $-4.982(171)$ & $<0.001$ \\
Family income (Malaysian ringgit) & $691.8(768.0)$ & $570.3(651.0)$ & $1.078(171)$ & 0.282 \\
Number of children & $4.4(2.8)$ & $5.0(3.0)$ & $-1.139(171)$ & 0.256 \\
Average birth spacing (years) & $2.4(1.4)$ & $2.9(2.1)$ & $-1.537(171)$ & 0.126 \\
Average months breastfeeding (per child) & $15.2(7.6)$ & $15.2(9.0)$ & $0.022(171)$ & 0.983 \\
Total knowledge score & $20.5(3.6)$ & $19.6(2.1)$ & $1.771(171)$ & 0.081 \\
\hline
\end{tabular}

doms, may not be available or accepted. Offering the broadest possible choice of methods may ensure better satisfaction and increased acceptance. In many countries, women do not have choices because national family planning programs could not offer comprehensive methods. ${ }^{22}$

The most popular method in our study was oral contraceptive pills, followed by injectables, traditional methods, IUDs, and implants. Pills and injectables are easily available at a minimum cost at government health facilities. Traditional methods such as herbal preparations are also easily available and inexpensive. However, none of the women in this study used other planning methods such as condoms, withdrawal, rhythm, spermicide, sterilizations, and exclusive breastfeeding. Permanent methods are not acceptable unless medically recommended. Our findings were slightly different from those reported by the Malaysian Ministry of Health, where the popular methods were oral contraceptives (73.1\%), followed by condoms (10.2\%), injectables (6.1\%), IUDs (4.8\%), and sterilization (4.5\%). ${ }^{3}$

In conclusion, the acceptance of family planning methods and the level of knowledge of women in these villages were poor. Health education campaigns are needed to educate women regarding the importance of family planning, choices of methods available, the effectiveness and side effects, as well as services available at the nearest health clinics. Proper education and counseling about contraceptives should be given to specific target groups, including the newlyweds, high-risk mothers, and those with unmet needs. Couples must be provided with proper knowledge of contraceptive methods to enable better decisionmaking regarding the frequency and timing of childbirth as well as the type of contraception appropriate for them. Active involvement of husbands, religious leaders, parents, and other influential adults may maximize the effectiveness of family planning programs. The husbands' knowledge of responsible parenthood and contraceptives should be upgraded because the success of the methods requires cooperation from both partners. Health education initiatives should be directed toward religious leaders who have important influence on the community to increase their level of knowledge and counteract biased information, beliefs, and myths relating to contraceptives.

\section{Acknowledgement}

We would like to thank the dean, School of Medical Sciences, Universiti Sains Malaysia (USM), for his encouragement and support. We also thank Associate Professor Halim Saleh; the USM Community, Family, and Case Studies (CFCS) program coordinator; and other panel members who approved the ethical aspect of this study. We express sincere gratitude to the second year medical and dental students of Group 3 who carried out the field survey, and our appreciation goes out to the village heads and all the villagers of Mukim Che Latiff, Kota Bharu, Kelantan.

\section{References}

1. Group 3 CFCS. Second year MD, 2004-2005. Community Profile and Resources in Mukim Che 


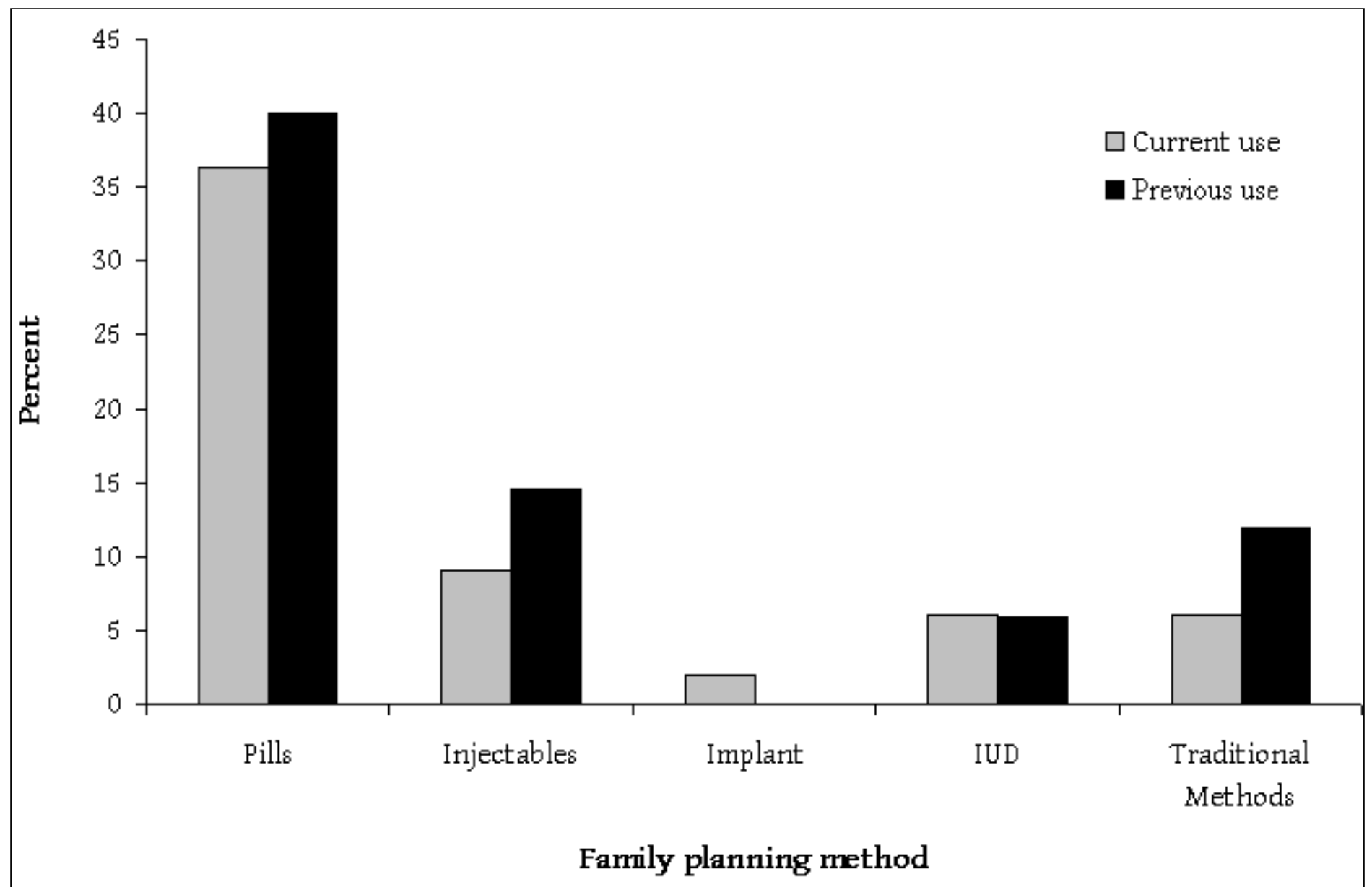

Figure 1. Percentage of use of family planning methods among villagers.

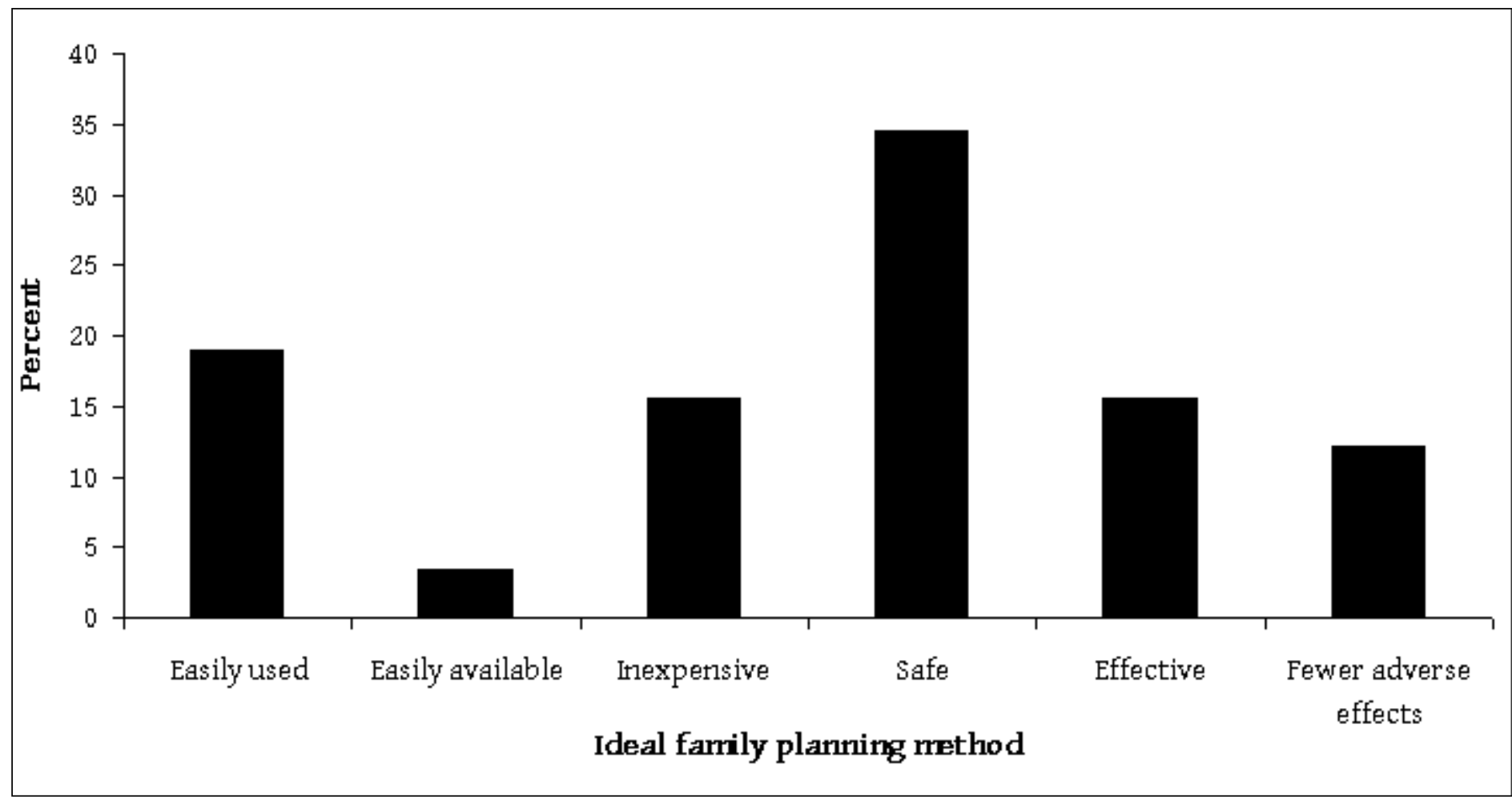

Figure 2. The criteria of an ideal family planning method according to the respondents. 
Latiff, Badang, Kota Bharu, Kelantan. School of Medical Sciences, Universiti Sains Malaysia; 2004.

2. Ministry of Health Malaysia. Annual report 2003. Division of Family Health Development. Kuala Lumpur: MOHM; 2003.

3. Ministry of Health Malaysia. Annual Report. Kuala Lumpur: MOHM; 2002.

4. Cammack M, Heaton TB. Regional variation in acceptance of Indonesia's family planning program. Popul Res Policy Rev. 2001;20(6):565-85.

5. Ngianga-Bakwin K, Stones RW. Birth intervals and injectable contraception in sub-Saharan Africa. Contracept. 2005;71:353-6.

6. Arshat H, Kader HA, Ali J, et al. The National Family Planning Program: its impact on perinatal mortality. Malays J Reprod Health. 1984;2(2):83-95.

7. Ince $\mathrm{N}$, Ayhan Ozyildirim BA, Irmak Ozden Y. The use of family planning methods in an administrative district of Istanbul. Eur J Contracept Reprod Health Care. 2003;8:21-6.

8. Martin $\mathrm{K}, \mathrm{Wu} \mathrm{Z}$. Contraceptive use in Canada 1984-1995. Fam Plann Perspect. 2000;32:65-73.

9. Paksima SM, Madanat HN, Hawks SR. A contextual model for reproductive health education: fertility and family planning in Jordan. Promot Educ. 2002;9(3):89-95,115,126.

10. Burkman RT. Patterns in contraception. Female Patient (OBS/GYN ed.). 2002;Dec supplement:8-11.

11. Sahin HA, Sahin H. Reasons for not using family planning methods in Eastern Turkey. Eur J Contracept Reprod Health Care. 2003;8:11-6.

12. Rama Rao G, Moulasha K, Sureender S. Knowledge, attitude and practice of family planning among fishermen in Tamil Nadu. J Fam Welfare. 1993;39(3):50-4.
13. Chandhick N, Dhillon BS, Kambo I, et al. Contraceptive knowledge, practices and utilization of services in the rural areas of India (an ICMR task force study). Indian J Med Sci. 2003;57(7):303-10.

14. Ying SL. Determinants of fertility in Malaysia -how much do we know? J Southeast Asian Stud. 1992;23:112-32.

15. Khor GL. Fertility preferences among Malaysian women: an analysis of responses to the new population policy. J Biosoc Sci. 1990;22:465-76.

16. Coulibaly S, Dicko F, Traoré SM, et al. Demographic Survey of Women Health in Mali 19951996: Family Planning Statistics. Ministry Of Women Health, Harmony and Elderly. [French] Bamako: Macro International; 1996.

17. Shah MA, Shah NM, Chowdhury RI, et al. Unmet need for contraception in Kuwait: issues for health care providers. Soc Sci Med. 2004;59:1573-80.

18. Underwood C. Islamic precepts and family planning: the perceptions of Jordanian religious leaders and their constituents. Int Fam Plan Perspect. 2000;26(3):110-7,136. Also available at http://www.guttmacher.org/pubs/journals/2611000 .html.

19. Swar-Eldahab AM. Constraints on effective family planning in urban Sudan. Stud Fam Plan. 1993;24(6 Pt 1):366-74.

20. Jones RK, Darroch JE, Henshaw SK. Contraceptive use among US women having abortions in 2000-2001. Perspect Sex Reprod Health. 2002;34(6):294-303.

21. Sterilization most widely used contraceptive methods in world. SIECUS Report. Dec 2002/Jan 2003;31(2):19-26.

22. WHO. Medical eligibility criteria for contraceptive use. 3rd edition. Geneva: WHO;2004. 